REVISTA ANDALUZA DE ANTROPOLOGÍA.

NÚMERO 3: MIGRACIONES EN LA GLOBALIZACIÓN.

SEPTIEMBRE DE 2012

ISSN 2174-6796

[pp. 51-79]

http://dx.doi.org/10.12795/RAA.2012.i03.04

Fecha de recepción: 22/05/2012

Fecha de aceptación: 12/07/2012

\title{
LA ACOGIDA A LOS INMIGRANTES: LOS CAMPOS DE INTERNAMIENTO
}

UBALDO MARTINEZ VEIGA

UNED (Universidad Nacional de Educación a Distancia)

\section{Resumen.}

En este artículo se estudia la última etapa del viaje de los inmigrantes irregulares. Se trata de los CIES o Campos de Internamiento de los Inmigrantes en Canarias, en Ceuta o Melilla, en Málaga, Madrid, Barcelona u otros sitios. Son lugares en donde se internan los inmigrantes durante un periodo máximo que hasta hace poco era de 40 días y ahora es de 60. Después de un viaje tan largo a través de África que ha tenido como efecto la ruptura de los lazos sociales con la familia, amigos o conocidos, se coloca a estos inmigrantes en una situación de aislamiento porque estos centros o campos se constituyen como una especie de espacios extraterritoriales en los que los inmigrantes cortan de hecho las relaciones con el lugar de origen y también las posibles lazos con el lugar de llegada. La misión fundamental de estos campos es conseguir la expulsión de los inmigrantes desde un país en donde todos los derechos son negados a otro en donde no tienen ningún interés en recibirlos. De alguna manera lo que se consigue con el internamiento es la constitución de los inmigrantes como extranjeros absolutos. La estancia de estas personas en estos centros es algo absolutamente superfluo e inútil que sirve para constituirlas como algo que sobra, como seres supernumerarios a los que ni siquiera se trata de educar ni de 
obligar a trabajar. En este artículo se estudian con una cierta detención las características de algunos de estos campos en España. También se dedica bastante espacio al origen que hay que buscarlo en el internamiento administrativo que aparece en Francia en 1914 y que se aplicaba a los argelinos, durante la guerra de Argelia, en donde se internaba a poblaciones por actos banales tales como la oposición de los llamados “indígenas" a los miembros de la administración o el peregrinar a la Meca sin permiso previo. Los Centros de Internamiento pasaron de Argelia a Francia y de aquí se difunden a través de los países europeos como un sistema de aislar y castigar administrativamente a los extranjeros.

Palabras clave: Inmigración, viaje, internamiento, campo.

\section{Abstract.}

This article studies the last part of the irregular immigrants' journey. It covers the CIES or Internment Camps for Immigrants in the Canary Islands, in Ceuta or Melilla, in Malaga, Madrid, Barcelona or other places. This is where the immigrants are interned for a maximum period, until a short time back, of 40 days and which now has become 60 . After such a long trip across Africa, whose main effect has been the rupture of all social and family ties, with friends or acquaintances too, these immigrants are now placed in an isolated situation where these centres or camps constitute a sort of extraterritorial space in which the immigrants in fact cut off all relationships with their place of origin as well as any possible links to their place of arrival. The fundamental mission of these camps is to expell immigrants from a country in which all Rights are denied to another which has not the slightest interest in receiving them. Their internment must in some way manage to convert these immigrants into absolute foreigners. Their stay in these centres is something absolutely superfluous and useless. It only serves to transform them into some sort of supernumerary beings whom they neither try to educate nor oblige to work. In this article, the characteristics of some of these camps in Spain are carefully studied. A considerable part concerns their origin which is to be found in the administrative internment in France in 1914 which was applied to the Algerians, During the Algerian war where populations were interned for banalities such as their opposition by the so-called "indigenous people" to members of the administration or for having been on pilgrimage to Mecca without prior authorisation. These Internment Centres went from Algeria to France and from here diffused through the European countries as a system to isolate and punish foreigners administratively.

Keywords: Immigration, travel /journey, internment, camp. 
Este artículo se basa en un trabajo de campo llevado a cabo en Madrid. El trabajo esta constituido por 80 entrevistas a inmigrantes negros africanos. Las entrevistas tuvieron lugar en Madrid en un Centro de Ayuda Católico que se llama Karibú. En el trabajo no se trata solo de describir lo que aparece en el trabajo de campo, sino de interpretar lo que significan los campos de internamiento tratando de descubrir su genealogía a nivel europeo.

Un 70\% de los entrevistados, al llegar a España fueron internados en unos centros que ordinariamente se llaman CIEs, (Centros de Internamiento para Extranjeros). Se trata de un fenómeno de carácter europeo y no se puede entender lo que ocurre en nuestro país sin tener en cuenta, por un motivo u otro, lo que pasa en Europa.

La primera cosa que llama la atención es la cantidad enorme de esfuerzo eufemístico que se ha llevado a cabo para designar estos lugares. En primer lugar, ha habido una tendencia generalizada a abolir la palabra "campo" para designar estos lugares, y la razón fundamental está en que esta palabra fue aplicada a los campos de exterminio, por ejemplo, nazi. Por ello, parecía un poco injusto comparar los centros de internamiento españoles con los campos nazis. Esto es absolutamente evidente y, por ello, estamos totalmente de acuerdo cuando Asier (2008: 271) se pregunta “a qué profundidad histórica y a qué fondo empírico puede referirse hoy una investigación sobre los campos? El modelo que se impone en lo que yo conozco de los campos actuales no es el del campo de la muerte, el campo nazi, cuya existencia brota de una lógica de exterminio y genocidio, pero que no se puede aplicar, hablando estrictamente, a la forma de campo como forma de poder o excepción". Por esta razón, no parece imprudente la utilización de la palabra campo aplicado a los campos de exterminio y a otros que no lo son. El intento de usar otras palabras para designar los campos que no son de exterminio corre el peligro de no entender que hay fenómenos comunes a los dos tipos que es esencial desentrañar. Por otra parte, esta especie de exorcisación lingüística corre el peligro de presentar estos lugares como una especie de "lugar de maravillas" en donde los derechos fueran tenidos en cuenta. Organizaciones como Migreurop siguen utilizando la palabra campo y muchas publicaciones, que están entre las mejores, y que se irán citando a lo largo de estas páginas, también lo hacen. Por ello, esta palabra va a seguir siendo usada junto con otras que se usan en la jerga oficial en España. El proceso de "eufemización" de lo que son los campos ha tenido sus apóstoles que lo han llevado a cabo con un tesón digno de mejor causa. Uno de ellos fue el Comisario Europeo de Justicia y Asuntos Internos, el portugués, Antonio Vitorino, que siempre rehusaba designar los lugares en los que se internaba a los migrantes irregulares o refugiados con el término "demasiado evocador" de campos (vid. Le Figaro, 2 de octubre de 2004, "L'Europe financera des "centres de refugiés" en Afrique du Nord). El Gobierno Español tampoco se ha quedado atrás en este proceso de creación de eufemismos. Courau (2007: 82-83) hace una comparación 
entre los diferentes nombres que se dan a estos campos en diversos países europeos. La comparación entre Bélgica, Italia, Francia, Reino Unido, Alemania y España da la palma de la economía a Alemania en donde se usa un único término. España es el país más prolífico con seis términos distintos. También es curioso constatar que ninguno utiliza la palabra campo. A pesar de ello creemos que la palabra campo debe ser usada porque tiene un carácter interpelativo y acusatorio que no hay porqué suprimir por una falsa idea de la neutralidad científica. Si yo dijera que Guantánamo no es un campo sino un "Centro Tropical de Redistribución de Migrantes Asiáticos" todo el mundo se reiría, pero a veces los eufemismos utilizados son parecidos a este.

De todas maneras, los CIEs o Centros de Internamiento para Extranjeros que fueron los lugares en donde fueron internados los migrantes africanos cuando llegaron a España son Campos en el sentido y con las características que vamos a describir a continuación. La denominación de estos lugares como CIEs ha durado hasta hace poco más de un mes cuando el gobierno del Partido Popular ha propuesto otro nombre nuevo.

En las entrevistas que se llevaron a cabo a los inmigrantes cuando se preguntaba por los lugares a donde eran llevados al llegar, hay dos respuestas que todos invariablemente daban. La primera era la denominación que daban a los lugares en donde eran internados. Invariablemente, decían que estos lugares eran prisiones o cárceles. En segundo lugar, cuando se preguntaba por las condiciones de estancia en estos sitios y, a veces, incluso sin preguntar nada, decían que la comida era muy escasa o que los mataban de hambre, otros decían que comer lo suficiente se convertía en una obsesión. Otros hacían también alusiones a la calidad deleznable de los alimentos. La respuesta de que el lugar en donde eran internados era una prisión es algo general entre los migrantes o refugiados que se encuentran en estos lugares. Asier, (2008: 207) dice que "los refugiados, desde hace más de 10 años, en el campo de Dadaab en Kenia hablan de su situación como la de una prisión... Sin embargo entre un refugiado de Somalia en el Campo de Kenia que se "siente" en prisión $y$ deprimido y otro en el centro de retención el CRA (Centro de Retención Administrativa) de Vincennes claramente "encarcelado" o "retenido" y maltratado a raíz de las bajadas nocturnas de la policía nacional no hay más que un golpe de destino, ninguna diferencia substancial de carácter moral o identitario".

La calificación de estos lugares como prisiones por parte de los que han sido internados en ellos es algo absolutamente general. Bietlot (2005: 223) dice que "más allá de las cuestiones jurídicas y lógicas, la vida cotidiana de los campos, tanto de un lado como de otro de la barrera, desmiente los argumentos de sus defensores. En todos los casos que conocemos, todos los migrantes que han tenido la desventura de pasar por ellos han experimentado una privación de libertad y evocan esta experiencia en términos carcelarios (y a veces peor aún). Además, si no se tratase de lugares de detención qué sentido tiene una infraestructura y tantos esfuerzos de vigilancia. Los campos en general están rodeados de alambradas altas o 
de grandes muros, de torres de control y de cámaras de vigilancia, de numerosos agentes de guardia... En el interior, cuando la infraestructura no permite una supervisión electrónica o por video (panóptica) los detenidos no pueden dar un paso, ni abrir una puerta, porque están todas cerradas con llave, sin ser escoltados por un guardia. Si el régimen varía poco en función del edificio, del tipo de población que encierra y de la duración de la detención, esta variación ya observada entre un centro y otro en Bélgica se amplía un poco entre un país europeo y otro, la lógica siempre es la misma: se trata de lugares de detención y no de espacios de libertad (!)".

Cuando yo preguntaba a los inmigrantes por qué llamaban a aquellos lugares en donde eran internados cárceles, algunos se irritaban y me preguntaban enfadados: “es que no sabes lo que es una cárcel?. Pues eso...".

Pero otros explicaban un poco más lo que allí ocurría y decían que estaban todo el tiempo vigilados por la policía que nunca se marchaba. Otros decían que "nunca les quitaban los ojos de encima". Cuando yo preguntaba por el maltrato, la mayoría respondía que no los habían maltratado. Otros respondían que la comida era poca y malísima y 4 ó 5 respondieron que los habían maltratado. Cuando pregunté en qué consistía esto, ninguno quiso explicarme nada y uno me dijo que tenía miedo de decirlo. Otros decían que los guardias gritaban mucho como si estuvieran enfadados, pero como ellos no entendían nada... Todos insistían en que lo más importante era "no decir" el país en el que habían nacido porque sino los volverían a llevar allí. Uno de los migrantes que había venido de Ghana y había estudiado tres años de ingeniería después de haber hecho la escuela técnica, cuando estaba explicando cómo lo más importante era ocultar la nacionalidad de origen, me dijo una cosa que me llamó mucho la atención: "Aunque no te lo creas, nosotros éramos apátridas, teníamos que esconder donde habíamos nacido y aquí vosotros no nos queréis...".

Si se quieren resumir los datos que hasta ahora hemos ofrecido hay que decir que la denominación de los lugares de internamiento era pura y simplemente de cárceles. También iban a insistir en que la comida era terrible y algunos veían esto como parte del maltrato. Otro elemento es el de la vigilancia continua por parte de la policía. Algunos hablaban del maltrato, pero la mayoría lo negaban. Es importante la observación sobre la situación de apátridas de los que llegan.

\section{DESCRIPCIÓN Y ANÁLISIS DE LA FORMA-CAMPO}

Siguiendo a Courau, se puede afirmar que hay una forma de gestionar la llegada de los refugiados o los inmigrantes sin papeles que se llama en unos lugares de Europa de una manera y en otros de otra pero que tienen una serie de elementos comunes, y, por ello, vamos a designarlos con la palabra campo. En el análisis histórico y a la vez sincrónico y comparativo van a aparecer algunos elementos importantes que ayudan a profundizar en 
los elementos estructurantes de las políticas con respecto a estos inmigrantes. Como ya hemos dicho, en España, los lugares a donde son llevados especialmente los inmigrantes que vienen en barcos, pateras o cayucos a las costas españolas se llamaban CIE, Centro de Internamiento para Inmigrantes. En Francia se llaman de otra manera, en Italia de otra y en Bélgica de otra. Sin embargo, aparecen algunos elementos comunes por debajo de estas diferencias terminológicas, y para designar esos elementos comunes vamos a usar la palabra "campo" que enseguida vamos a definir. Uno de los especialistas más importantes sobre los campos en Europa, Bernardot (2002; 2003; 2004; 2005a y 2005b), en una conferencia impartida el 25 de enero de 2002 (ms) y que se titulaba "Existe-t-il un modèle français du camp?", trae a colación la definición de campo que había ofrecido hacía tiempo Roland Barthes.

Según ella, un "campo" "es un reagrupamiento impuesto y arbitrario de civiles fuera del sistema penitenciario con una duración indeterminada que va dirigido a encerrarlos, reeducarlos o hacerlos trabajar", los campos a los que nos referimos son distintos de lo que podíamos designar como establecimientos disciplinarios. En estos últimos se intenta que la gente detenida tenga que trabajar o disciplinarlos para obtener individuos útiles y dóciles. Nada de esto tiene lugar en estos Campos. Aquí lo único que se lleva a cabo es el aislamiento e inmovilización momentánea. También se trata de intimidarlos y disciplinarlos para prepararlos en principio para su repatriación forzada. Estos campos son lugares en los que los inmigrantes sin papeles, a su llegada al país de destino, son reunidos, controlados y retenidos con un fin preciso que es, ni más ni menos, que expulsarlos a su país de origen. De paso, la presencia de estos inmigrantes en estos campos se manifiesta como algo absolutamente inútil, como un lugar en donde no se intenta conseguir nada útil de la gente retenida ni tampoco reformarla ni educarla. La estancia de las personas en estos lugares es algo superfluo e inútil que hace inútiles a las propias personas que se encuentran dentro de ellos. En estos lugares no se pretende realmente hacer nada con las personas que se internan en ellos. Se trata únicamente de atemorizarlos y echarlos fuera del país al que han llegado. Se les echa porque sobran, son, como diría Mike Davis, supernumerarios, personas que sobran. Este carácter superfluo que subraya la inutilidad de los campos y de la estancia de los inmigrantes en ellos fue subrayado hace ya más de cincuenta años por Arendt cuando hablaba de la situación de aquellos que ella llamaba los "sin Estado." Caloz-Tschopp (2000), quizás la mejor intérprete del pensamiento de Arendt, incluye dentro los que ella designaba como "los sin estado" "los refugiados que están dentro de un campo o que van de un sitio para otro, las minorías en el exilio, los desplazados internos, los que son rechazados en los países de llegada, (los sin papeles), es decir el conjunto de todos aquellos que hoy día están desenganchados de todo sistema político que pudiera darles un lugar, protegerlos". 
Pero, para comprender el alcance de esta situación, parece conveniente plantear dos cuestiones básicas. La primera se refiere a la evolución histórica y también conceptual de estos campos y la segunda se refiere al problema de los derechos o de su ausencia. Como ya hemos dicho, el término que se usaba para designar los campos en los que se colocan estos inmigrantes sin papeles es el de "Centro de Internamiento para Extranjeros". La primera cosa que llama la atención es la cualificación de estas personas no como migrantes, o inmigrantes o demandantes de admisión al país, o la que sea... Se califica a estas personas como extranjeras, y que por lo tanto no tienen absolutamente nada que ver con España. "Pasaban por aquí, y resulta que pusieron su pie en tierra” como lo podían haber puesto en otro sitio.

Pero quizás lo más interesante sea la idea de "centro de internamiento," y quizás el país en donde se da una tradición más larga de lo que se llaman centros de internamiento sea Francia, por ello se va a analizar lo que allí ha ocurrido y ello nos va a ofrecer una dimensión bastante clara de lo que estos campos significan en España. Para analizar esta historia nos vamos a fijar en las observaciones de Bernardot que se han citado hace un momento, así como en los análisis de Le Cour Grandmaison (2007). Lo que se llama el internamiento administrativo que es de lo que se trata aquí fue definido en Francia por una orden ministerial de 1834 y de agosto de 1845. Estaba motivado por la guerra de conquista en Argelia y, como es obvio, nace de lo que se consideraban los imperativos de la guerra y por lo tanto en un cierto estado de excepción. Este fenómeno no aparece únicamente en Francia. El filósofo italiano Agamben (1955: 48), que ha sido uno de los grandes estudiosos de los campos, subraya con razón que la "Schutzhaft" o la detención preventiva es una institución de origen prusiano que, dentro del estado de sitio, permite encarcelar a todos aquellos que son considerados como una amenaza a la seguridad del estado. En 1871 se extiende a la casi totalidad del territorio alemán y esta disposición fue usada de una manera masiva por las autoridades durante la primera guerra mundial. En Francia el internamiento se convierte en una sanción permanente que se separa del contexto de excepción o de guerra. Como muy bien dice Le Cour Grandmaison (2007:31): "el internamiento sobrevive a casi todos los cambios de régimen que tienen lugar en la metrópoli dado que fue confirmado por una decisión ministerial del 27 de diciembre de 1897".

Con este proceso lo que se está iniciando es un proceso de banalización por el cual no se piensa en el internamiento ni en los campos como fenómeno excepcional que se sale del derecho ordinario, que incluso representa un atentado a derechos fundamentales tales como la libertad de circulación o incluso al estado de derecho (privación de libertad sin intervención de un juez). Esta banalización tiene lugar en Francia porque poco a poco el internamiento se considera como una disposición común para los árabes. En 1914, Benhabiles (1914) decía que “había, además, una pena aplicada especialmente a los 
indígenas, el internamiento administrativo, que no está previsto en ningún texto y que no tiene ningún procedimiento de aplicación". De poco vale que en aquellos momentos, haya voces que se levantan con lo que consideraban justamente una aberración, dado que el internamiento administrativo se va imponiendo. En el mismo año 1914, el diputado Charles Dumas decía que "está en las manos de la administración un arma más terrible que la del indigenado... y este arma terrible, odiosa e ilegal, es el internamiento. La definición jurídica del internamiento es algo imposible pues no corresponde a nada equivalente en el derecho francés; no se basa en ningún principio conocido".

A pesar de que parece evidente que es una especie de anomalía y contradicción jurídica que no responde a ningún principio de derecho existente, sin embargo, el internamiento se impone de "facto" y se banaliza, aplicándolo a situaciones prácticamente sin importancia. La oposición de los llamados indígenas a los miembros de la administración, el robo de ganado o la peregrinación a la Meca sin permiso previo pueden llevar a la pena del internamiento. La aplicación de esta pena por actos banales hace que lo excepcional se convierta en regla. Por ello aparecen teóricos que lejos de limitarla pretenden ampliar su aplicación. Laacher y Rechtenwald (1923) dicen que "lo que interesa sobre todo son los buenos resultados que la pena de internamiento produce. Además, parece que el internamiento aplicado de una manera metódica a ciertas categorías de malhechores podría ofrecer un servicio considerable a la colonia. Lejos de plantear su supresión, hay que favorecer su extensión".

Aparece aquí claramente una visión que tiene únicamente en cuenta los resultados represivos, lo cual implica que la ley que en un primer momento tenía que ver con una situación excepcional, de estado de excepción, se convierte en algo ordinario y banal y por ello se trata de generalizarla. Es también importante tener en cuenta no sólo lo que dice sino quién es el que plantea la cuestión de esta manera. El Profesor Laacher es considerado como la autoridad más importante con respecto a los problemas legislativos y penales dentro de la colonia que es Argelia.

Si seguimos analizando lo que esta ley del internamiento representa, aparecen algunos elementos que pueden parecer extraños pero que cuando se comparan con la situación actual, no se puede decir que sean realmente muy diferentes.

La primera característica que llama la atención es que la duración de la pena es siempre algo indeterminado. Además de ello, ni el sitio ni la forma de detención o internamiento están determinados. Hace poco fue sometido al parlamento español la ley de inmigración. "La norma pretende incorporar varias directivas europeas como la que amplía el tiempo máximo de retención de sin papeles y el Ejecutivo considera que no sería conveniente iniciar la Presidencia Europea sin cumplirlas" (El País 5, de julio de 2009). Se presenta en este momento la ampliación de la retención de los que no tienen papeles que pasa de 40 a 60 días. Realmente nadie que se plantee el problema de una manera racional 
puede justificar este alargamiento. Tampoco se puede negar que se da un cierto cinismo por parte del Ejecutivo con respecto a este problema como si este alargamiento de la retención fuera algo que impone la Unión Europea, cuando en las deliberaciones previas, el Gobierno Español había defendido el alargamiento del periodo de internamiento de 40 días, como está en este momento, hasta 60 días.

Efectivamente, "el Gobierno Español insistió ayer en que apoyará la directiva europea de repatriación de inmigrantes ilegales que impone máximos de detención para los sin papeles de hasta 18 meses y que una decena de países quiere endurecer" (El Mundo, 9 de mayo de 2008).

De hecho, el 7 de mayo de 2008 se debatió la directiva europea para "los sin papeles o la directiva de la vergüenza”, como se la ha llamado. La Comisión había presentado un proyecto hacía dos años que ofrecía muchas más garantías que la directiva actual. El proyecto inicial exigía que las órdenes de internamiento se dictaran "por autoridades judiciales. En la directiva tal y como se presenta ahora el internamiento podrá ser decidido por las autoridades administrativas o judiciales" (El País, 7 de mayo 2008). En casos urgentes, en el proyecto inicial se permitía la detención por orden administrativo pero “debía ser confirmada por las autoridades judiciales en el plazo de 72 horas". En la nueva propuesta, en el supuesto de que el internamiento haya sido ordenado por una autoridad administrativa, los Estados "dispondrán el control judicial lo más rápidamente posible" pero no se fija un límite temporal. Como se puede observar, lo que aquí ocurre es que se da un poder muy grande a la autoridad administrativa que está en la línea de los primeros planteamientos que en Argelia hacían los franceses cuando planteaban el problema del internamiento a mitad del siglo XIX. Este fenómeno tiene una gran importancia y más adelante vamos a analizarlo más detenidamente.

De todas maneras, hay que subrayar que tanto la Asociación de inmigrantes ecuatorianos Rumiñahui como la asociación marroquí ATIME "expresaron su rechazo a que la Administración pueda decretar la orden de internamiento de estas personas y no los jueces" (El Mundo, 9 de mayo 2008). Es claro que esto representa un recorte enormemente importante de los derechos. Lo que se propugna en la directiva es la admisión de la administrativa como vía ordinaria con confirmación judicial lo antes posible. De todas maneras, el plantear el problema como si se tratase de una imposición de la Unión Europea es algo que no se sostiene. Como muy bien se decía en el periódico El País (7 de mayo, 2008), "la posición de España será decisiva. Si la directiva se aprueba hoy con el texto actual, entonces ya sólo quedará pendiente de su aprobación por el Parlamento Europeo, el 5 de junio". La razón por la que la posición de España es decisiva, es porque para la aprobación de la directiva se requiere mayoría absoluta y sin los votos españoles esto no se consigue. Para lograr la minoría de bloqueo y con ello parar la directiva se necesitan 80 votos y España tiene 27. Hay otros elementos preocupantes en esta directiva 
europea. La Ley de Extranjería que, como todo el mundo sabe no es precisamente un dechado de defensa de los "derechos y libertades" de los inmigrantes irregulares dice en su artículo 62.3: "El internamiento se mantendrá por el tiempo imprescindible para los límites del expediente sin que en ningún caso puede exceder de 40 días, ni acordarse un nuevo internamiento por cualquiera de las causas previstas en un mismo expediente. La decisión judicial que lo autorice atendiendo a las circunstancias concurrentes en cada caso, podrá fijar un periodo máximo de duración del internamiento inferior al citado". El Reglamento de Extranjería (artículos 153.3 y 153.5) parece incluso más claro: "El ingreso del extranjero en un centro de internamiento... no podrá prolongarse más tiempo del imprescindible para la práctica de la expulsión. La duración máxima del internamiento no podrá exceder de 40 días y deberán solicitarse de la autoridad judicial su puesta en libertad... cuando con anterioridad al transcurso de este plazo se tenga constancia de que la práctica de la expulsión no podrá llevarse a cabo". En España el plazo máximo va a ser de 60 días. La directiva de la U.E. permite la retención hasta "18 meses en los que pueda prolongarse la operación de expulsión debido a la falta de cooperación del afectado o por demorar en la obtención de la documentación necesaria que deban expedir terceros países" (El País, 9 de mayo 2008).

La explicación de la razón por la cual España va a aceptar esta directiva de la Unión Europea es expuesta con toda claridad por el Señor López Garrido, Secretario de Estado para la UE y por el Señor Pérez Rubalcaba, Ministro del Interior, así como por algunos expertos de la Comisión Europea. Si empezamos por los expertos de la Unión Europea, se puede observar algo que llama la atención. "Para cualquier indocumentado en los veintisiete (países) el castigo extra, además, será la prohibición de entrada en todo el territorio europeo en los siguientes cinco años y durante un periodo más largo si ha cometido algún delito. Los expertos de la Comisión insistieron ayer en que esta parte es fundamental para mandar la "señal" de que "no es una buena idea" entrar sin papeles en Europa” (El Mundo, 9 de mayo, 2008). Lo que aquí se está afirmando ha sido desarrollado previamente por los estudiosos del problema. Con una política dura de internamiento se trata antes de todo de "hacer teatro" y de enviar una doble señal. Por una parte, a los candidatos a migrantes se trata de enviarles un mensaje significando que la política de lucha contra la inmigración clandestina (internamiento-retorno), se va a llevar a cabo con firmeza - es lo que se llama la señal fuerte (“imirad lo que os espera!”). Por otra parte, se da un mensaje a la opinión pública interna, a quien se espera demostrar que el problema se toma en serio (“iFijaros, lo tomamos en serio!”) (Intraud y Perrouty, 2005: 87). Con la pena de no poder volver a entrar en la Unión Europea en cinco años después de ser expulsados, los expertos europeos piensan que están mandando una señal fuerte a los que quieren volver a entrar en la UE después de haber sido expulsados de ella. Si no fuera porque se trata de una situación trágica, casi da la risa y uno tiene ganas de preguntar si para aquellos que no han sido expulsados la entrada va a ser facilitada (!). 
Con respecto a la señal que se intenta enviar a la opinión interna, quizás este sea el problema más importante en la constitución de la política (sobre todo la represiva) migratoria. En el programa del Partido Socialista presentado en las pasadas elecciones de 2008 se repetía una frase que no había llamado mucho la atención: "Endurecer la lucha contra la inmigración irregular". En el programa del PSOE se decía: "Los socialistas nos comprometemos a modificar el actual periodo máximo de detención de los inmigrantes irregulares en los Centros de Internamiento de Extranjeros (CIE) ampliando a un periodo homologable con el resto de los Estados miembros de la Unión Europea y que permita el tiempo necesario para llevar a cabo los trámites de identificación y repatriación de los inmigrantes irregulares". En este caso se trata en gran medida de enviar un mensaje a la población autóctona en el sentido de que se toma en serio el problema de la legalidad/ regularidad de los inmigrantes, y que, por lo tanto, aquellos que son irregulares serán tratados con toda la dureza de la ley que se va a hacer más dura todavía.

Además de todo esto, hay que llevar a cabo todo un proceso de "magnificación de la importancia de la regularidad, del tener papeles." Como todos saben, al menos hasta ahora, el no tener papeles es una falta puramente administrativa que tiene una importancia menor. Sin embargo de lo que tratan los Gobiernos europeos, y en concreto el español, es de magnificar la importancia del carácter regular o irregular de los inmigrantes que es un proceso que está presente desde que se empezaron a dar regulaciones sobre la inmigración. Poco a poco el carácter "irregular" de la inmigración se convierte en un "master status-determining trait" (Engbersen, 2001: 19), en "un esquema central y director de asignación de estatus." Este fenómeno es puramente arbitrario y uno de los factores fundamentales de la creación de este esquema es el propio endurecimiento de las leyes con respecto a los inmigrantes sin papeles que tiene un carácter tan arbitrario como la misma idea de su importancia. Sin querer entrar en el análisis pormenorizado de este fenómeno que bien podría ser objeto de un libro entero, queremos subrayar únicamente una o dos observaciones de algunos políticos españoles que se refieren a este problema. La primera afirmación viene de Diego López Garrido, Secretario de Estado Español para la UE, que dice que "España y sus socios comunitarios quieren alentar la inmigración legal y desalentar la ilegal”. El mensaje de los veintisiete, según insistió en Bruselas el nuevo Secretario de Estado, debe ser que "el inmigrante que está en situación ilegal en un país europeo tiene un destino: el retorno". Al leer estas frases uno se acuerda inmediatamente de una frase que repite continuamente el Ministro del Interior referente a los miembros de ETA cuando dice que los Etarras "no tienen más que una salida: la cárcel”. Es evidente que aquí se trata de una contaminación semántica que, quizás sin querer, está estableciendo un cierto paralelismo entre los etarras y los inmigrantes sin papeles.

El Ministro del Interior justifica el endurecimiento de las leyes sobre la inmigración irregular diciendo que "si somos laxos con la inmigración ilegal, la avalancha no hay quien 
la pare" (El País, 9 de mayo 2008). Tanto el Señor López Garrido como el Señor Rubalcaba, en estas afirmaciones están mostrando ciertas tendencias a la semiología. López Garrido habla de "mensaje" y Rubalcaba va a insistir en que la laxitud con la inmigración irregular favorece la "avalancha" porque quizás envía el mensaje a "los millones de personas que están en las puertas del país" de que es fácil entrar y van a llegar como una especie de diluvio que va a desintegrarnos como país.

Quizás sea bueno recordar lo que representa esta idea de la avalancha. De nada sirve decir que nunca ha habido ninguna avalancha. Que esta palabra fue acuñada por un racista norteamericano Frank Warne (Martínez Veiga, 2007), y que posteriormente fue usado con las mismas connotaciones por Margaret Thatcher. Además de esto es importante subrayar que a pesar de las afirmaciones sobre el destino de los inmigrantes irregulares, "España sólo logra repatriar a uno de cada cinco inmigrantes que residen sin permisos legales en territorio nacional. En el 2007 se quedaron en el país 36.176 "sin papeles", a pesar de que las Fuerzas de Seguridad les localizaron y llegaron a incoar los correspondientes expedientes de expulsión, según estadísticas del Ministerio del Interior a los que el departamento nunca ha dado publicidad" (El Norte de Castilla, 9 de mayo 2008).

Según el Ministerio del Interior en 2007 fueron deportados a sus países 55.938 inmigrantes. El 83\% fueron deportados desde la frontera, pero todos reconocen que la principal vía de entrada de inmigrantes irregulares son los aeropuertos. No se tienen estadísticas fiables sobre los que han llegado con visado de turista y una vez que se ha terminado el plazo del visado de turista se quedan en España. La mayoría de estos inmigrantes son de origen latinoamericano, se convierten en "sin papeles" e inexpulsables, aunque tengan incoados expedientes de repatriación. Esto es lo que se llama "irregularidad sobrevenida." Con esto se produce "de facto" un fenómeno de discriminación de los inmigrantes africanos que son expulsados en un porcentaje mucho mayor que los latinoamericanos que se quedan. Con ello, quizás se pueda decir que hay una discriminación en base al color de la piel, o, quizás, de una manera más exacta, en razón de la pobreza de los que llegan, dado que hay que tener en cuenta que los africanos negros son siempre los más pobres.

Hay que subrayar que los centros o campos de internamiento tienen una eficacia escasa. Si se entiende por eficacia el número de personas que se devuelven en relación a las personas internadas, hay que decir que esta eficacia no parece excesiva. Pero, tanto en el caso español como en el caso europeo, es muy difícil obtener estadísticas o simplemente datos porque los Ministerios del Interior no los dan con facilidad.

"En Francia a partir de estadísticas calculadas en un tiempo de 10 años, (1992-2002), la CIMADE, (una organización católica de ayuda), calcula que de media un 50\% de los extranjeros internados son efectivamente expulsados, con una disminución progresiva de la tasa de expulsión que va del 61\% en 1992-1993 al 36,6\% en 2002" (Intraud y Perrouty, 2005: 87). Las estimaciones de carácter europeo son todavía más difíciles de obtener, 
pero se suele estimar, y yo lo he oído en diversos foros, que la eficacia de los centros de internamiento se sitúa más o menos entre el 40 y el 60\%. Se trata de una eficacia baja que indica que los efectos son discutibles. Muchos estudiosos afirman que se trata más bien de una eficacia en el orden simbólico. Es decir, se trata de los mensajes o señales que se intentan mandar tanto a la población que intenta migrar como a la población receptora de inmigrantes. El problema se complica porque la eficacia de estos mensajes es todavía más discutible y llega poco más allá de decir que "si no tenemos mano dura, adonde vamos a llegar" o "hay que ponerse serios porque sino nadie nos toma en serio." Esto como se ve no tiene visos de ser muy exacto desde el punto de vista científico.

De todas maneras, en El País (9 de mayo de 2008), el Señor Rubalcaba hacía unas declaraciones que son interesantes, en las que decía que las repatriaciones "son las decisiones más difíciles que toma un Ministro del Interior. La noche que sale un vuelo de Canarias a un país de África, esa noche no se duerme bien, porque uno piensa en la gente que se ha jugado la vida y que tiene que volver". No se quiere comentar esta afirmación que se comenta sola. Lo único que se quiere decir es que el ejemplo que el Ministro pone es la salida de un vuelo de Canarias con africanos negros que son los que en mayor proporción se repatrían.

La razón que el ministro ofrecía para la ampliación del plazo de retención desde 40 a 60 días está en lo corto que es el tiempo para poder expulsar a los inmigrantes irregulares. Un grupo de juristas: Grupo Inmigración y Derecho Penal (Público, 10 de julio 2009), dentro de la crítica a la nueva ley de extranjería, que estaba todavía sin aprobar dice, por boca de Margarita Martínez Escamilla, que "lo más grave es la ampliación a 60 días (del internamiento)", dado que implica un recorte grave e injustificado de los derechos de los internados. "Los juristas aseguran que la ampliación de las retenciones a 60 días aumentará la población de inmigrantes internados porque los encierros durarán un 50\% más y no se prevén medidas para hacer frente a este incremento" (Público, 10 de julio 2009).

De todas maneras, es importante comprender que todas las explicaciones acerca de la retención e internamiento de los extranjeros sin papeles son ininteligibles en España sin compararlas con lo que ocurre en otros países de la UE. Por ello, estamos tomando la historia de este fenómeno en Francia porque es un caso paradigmático que puede explicar lo que en estos momentos ocurre en nuestro país.

De todas maneras, este alargamiento irracional del periodo de retención tiene que ver con la idea original del internamiento indeterminado en el tiempo que se imponía en Argelia por parte de las autoridades francesas. En un principio se piensa que el internamiento no tiene límites temporales y es curioso que en este mismo momento hay países en la UE en los que no hay límite temporal al internamiento de los inmigrantes sin papeles, con lo cual hay que comprender cómo se ha avanzado poquísimo desde la mitad del siglo XIX. Sin embargo, es curioso que un fenómeno como el alargamiento del periodo 
de internamiento desde 40 a 60 días se haya presentado en España como una especie de ordenación de tipo benevolente. La idea subyacente es bastante fácil de comprender. Se dice, a pesar de que nosotros estamos autorizados a ampliar el periodo de retención, no lo ampliamos más que desde los 40 a los 60 días y no propugnamos un alargamiento mayor o incluso una duración sin límite fijo. Sin embargo, no se comprende que precisamente se puede permitir la ampliación desde los 40 a los 60 días porque se piensa que la duración del internamiento podía ser indefinida como era en un primer momento. El alargamiento del internamiento desde los 40 a los 60 días es una concretización de la idea de que el internamiento y la retención no tienen límite temporal, y no es de ninguna manera algo que se contrapone a ello como el Ejecutivo español quiere hacer creer.

Le Cour Grandmaison (2007:33) explica perfectamente lo que significaban estas normas de internamiento. "El internamiento se impone al que va a ser internado, sin que sea necesario hacerlo comparecer, y no termina más que por una orden de aquel que lo ha impuesto. Los hechos del internamiento, durante mucho tiempo, no han sido definidos en un texto. En contra de todos los principios que se refieren a la separación de poderes y a las penas de privación de libertad que, según la Declaración de los Derechos del Hombre y del Ciudadano, pertenecen al campo de ley, un agente administrativo - este es el estatuto jurídico del Gobernador General- tiene la posibilidad de internar a las personas en las condiciones que conocemos". Aparece aquí un elemento que se va a mantener desde entonces a nuestros días y que más adelante hay que analizar con detenimiento. La persona que determina, en el caso de Francia en Argelia que es al que nos estamos refiriendo, la duración del internamiento, las condiciones e incluso, en aquellos años, el lugar, era una autoridad administrativa. Enseguida se va a poder analizar lo que esto significaba en aquel tiempo y lo que significa en este momento, que, ya lo adelantamos, no difiere mucho. La medida de internamiento era una medida de excepción o de fuerza que ya en la época en la que fue promulgada y llevada a la práctica era considerada por algunos juristas (Massonié, 1909) "como una ilegalidad, un abuso de poder que está en contradicción con los principios establecidos en materia de represión". Un delincuente, un criminal, o un prisionero ordinario de guerra, que han cometido algún delito son juzgados en base a normas y disposiciones claras y precisas. Estas determinan los procedimientos, la naturaleza y las condiciones de ejecución de la condena, la duración y las posibles apelaciones contra la condena. En el caso del "indígena" que ha sido internado, este no puede ser considerado como un prisionero que cumple una condena que le haya sido impuesta por un juez, ni como alguien que ha sido acusado, que al ser encarcelado no pierde sus derechos y esto le permitiría defenderse. La persona internada, en este caso el argelino, se encuentra en una situación en la cual, en base a una decisión administrativa, toda ley queda abolida hasta que no deja de estar internado. Desde este punto de vista, el internamiento tiene como efecto privar a la persona de su libertad y abolir en el mismo momento y de una manera básica su condición de titular de derechos. 
Parafraseando a Arendt, que en su obra utilizó muchos datos de la situación colonial argelina, hay que decir que lo que con el internamiento se consigue, es constituir a los individuos como individuos sin Estado, es decir una persona sin ejercicio de ciudadanía, sin el derecho a tener derechos. Como muy bien explica Grandmaison (2007), "el que ha sido internado no puede ser considerado ni como un individuo, no siquiera como un hombre en el sentido jurídico del término, porque no goza de ninguno de los derechos que van unidos a esta condición. Situado en el rango de la pura vida, sujeta a un encarcelamiento inmediato y sin fin, está totalmente a disposición del que detenta la autoridad, que puede disponer de él como le place, si bien no tiene la posibilidad dentro de este marco de condenarlo a muerte". De todas maneras, es importante subrayar que para comprender la historia jurídica y política de la idea y la práctica del internamiento hay que tener en cuenta que es un sistema represivo de excepción, que se sustrae a todos los procedimientos judiciales normales. A los que son internados o retenidos se les aplica una decisión administrativa bastante sencilla, es decir un "infra-derecho" en el cual se niegan los derechos fundamentales. Como ya hemos dicho, en el caso francés que es paradigmático y sirve para sacar a luz muchos elementos de las prácticas españolas al respecto, las prácticas del internamiento son desarrolladas a partir de disposiciones coloniales que fueron propuestas desde los años 1830. Estas ideas y prácticas fueron probadas sobre los “indígenas" de Argel. En 1955 se proclamó el estado de excepción o urgencia en Argelia y, entonces, se decide que, tanto el Gobernador como el Ministro del Interior, pueden internar a todo individuo que sea juzgado peligroso para el orden público. En 1956 el Gobierno de Guy Mollet obtiene poderes especiales por los cuales en 1957 se permite aplicar el internamiento dentro de Francia y se crean cuatro campos dentro de la metrópoli. En el momento de la independencia había 5.000 argelinos internados en estos campos.

Posteriormente, tres días después de la aceptación de la Constitución de la $5^{\text {a }}$ República aparece una Orden de 7 de octubre de 1958 que permitía internar en Francia “incluso a las personas peligrosas para la salud pública por la ayuda material, directa o indirecta que ofrecían a los rebeldes argelinos" (Grandmaison, 2007: 38). Hay que subrayar tres cosas en todo este panorama. En primer lugar, el internamiento se aplica básicamente a los extranjeros. En segundo lugar se trata de algo que se banaliza continuamente, y en tercer lugar es un fenómeno que tiene un carácter expansivo.

El derecho de retención que es un aspecto central del internamiento tiene vigencia en Francia a partir de 1810, en base al artículo 120 del Código Penal en el que se castigan a los guardianes y conserjes de las casas que hayan detenido a un prisionero sin orden de arresto. Pero, y esto es importantísimo, se establece la excepción de que esto es legítimo cuando se actúa por "una orden provisional del gobierno." Hay que utilizar la provisionalidad de la orden que hace que la retención administrativa sea considerada legítima hasta 1981. Este año la ley Questiaux suprime "la orden provisional del gobierno. En 1914, se da una 
circular por la cual el Ministerio del Interior confía a los prefectos la gestión de los campos en donde se van a internar los "austro-alemanes" pero también los escapados de la justicia o las "mujeres públicas, los nómadas y los sin techo"... Es importante subrayar que no se internan sólo extranjeros sino también franceses e incluso se puede pensar que se trata de un fenómeno que tiene una enorme ambigüedad lo cual es un problema presente hasta nuestros días. Esto se ve fácilmente en el carácter excepcional que, únicamente de palabra, se le daba. Por otra parte se presentaba con unas características ambiguas que unas veces se presentaban como protección de los internados y otras veces como pura represión y la mayoría de las veces como una mezcla de los dos fenómenos, incluso, otras veces no estaba claro si con el internamiento se intentaba colocar en otro sitio a las personas o más bien ayudarlas a que vayan de un sitio a otro.

Bernardot (2007: 46) dice con toda la razón que "el hecho de que el internamiento pueda afectar a todas las categorías sociales, de género y edad sin distinción previa, le da una gran flexibilidad en relación con otros espacios represivos. Las diferenciaciones se llevan a cabo como un laboratorio en el que la administración instaura y multiplica las categorías y jerarquías bajo criterios policiacos, étnicos, utilitarios o sanitarios en función de las circunstancias. En los primeros tiempos del internamiento, las autoridades multiplican los tipos de campos que se piensa que están adaptados a los objetivos que se persiguen y a las características de sus ocupantes. Aparecen, por ello, campos más o menos represivos, más o menos grandes, más o menos duraderos. Esto influye sobre la vigilancia, el equipamiento $y$ las posibilidades de instalación de los internos". Pero, poco a poco, se va creando una especie de elementos comunes que constituyen desde un punto de vista reglamentario (leyes, normas y regulaciones con frecuencia absolutamente absurdas), una especie de núcleo que se aplica no sólo a los campos de internamiento sino a otros establecimientos tales como albergues, lugares de acogida, etc.

En Francia, y esto va a ser una característica típica también en el caso español, los campos de internamiento se instalan en edificios que ya estaban construidos y que habían sido abandonados, tales como cuarteles abandonados, edificios eclesiásticos, instalaciones de carácter industrial, o simplemente edificios que habían tenido una utilidad colectiva. Desde este punto de vista, se distinguen estos lugares de los "Lager" alemanes que se basaban más en un modelo de carácter militar. En el caso francés es importante subrayar que es el internamiento colonial (el internamiento de los extranjeros) lo que sirve de modelo y banco de prueba para los otros tipos. El internamiento se aplicaba fundamentalmente a los argelinos, que en cuanto "Árabes," se consideraban enemigos no convencionales y por ello debían ser castigados de una manera no convencional, sin derechos, y en base a un principio de carácter administrativo. Esta idea de los enemigos no convencionales o las "personas gravemente problemáticas de carácter no convencional" va a estar presente en los centros de internamiento desde la mitad del siglo XIX en Francia 
hasta Guantánamo o los CIEs en España. Este carácter “no convencional” de las personas que se internan, normalmente, no quiere decir nada más que algo tan simple como que son extranjeros, que no tienen papeles o que no tienen la nacionalidad. Algo tan banal como esto se convierte en una especie de mundo que permite todo tipo de tropelías. En África Ecuatorial, Francia introduce el internamiento administrativo y se descubre que esta pena podía ser aplicada a los indígenas por "crímenes tan graves" como "no haber saludado al comandante o la bandera francesa." La condena, llevada a cabo sin ningún juicio, se aplicaba a una persona que no era francesa, ni tenía ninguna posibilidad de adquirir la nacionalidad.

El internamiento de tipo colonial se lleva a cabo en las colonias, pero este mismo fenómeno tiene lugar en la metrópoli, como ya hemos visto desde 1910. Es muy importante observar lo que ocurre en la III ${ }^{\text {a }}$ República cuando se plantea el problema de los extranjeros que están en territorio francés. En 1938 desde el Ministerio del Interior, dirigido por Albert Sarraut que había tenido mucha importancia en las colonias, se promulga un Decreto Ley, en el cual en base a la seguridad nacional y a la protección del orden público, se decide colocar en "centros especializados los extranjeros que, sin haber cometido ninguna infracción, se pensaba que eran indeseables para las autoridades". En el preámbulo de este decreto se decía: "En el interés por el orden y la seguridad pública (estos extranjeros) serán sometidos a medidas de vigilancia más estrecha ... y serán obligados a residir en uno de los centros que serán designados por decreto". Los primeros que van a ser victimizados, por este y otros decretos, serán los republicanos españoles que vienen a Francia buscando refugio después de la victoria fascista durante la "Retirada".

En 1939, se promulga otro decreto que en su inicio dice: "El número creciente de extranjeros residentes en Francia impone al gobierno que está investido de poder legislativo en un campo definido, dictar algunas medidas exigidas por las necesidades de la seguridad nacional, por la economía general del país y la protección del orden público".

Pechanski (2002) dice que, en este momento por primera vez, después de la primera guerra mundial se impone el internamiento administrativo a grupos de personas que residen en Francia. "De hecho se trataba de una ley sobre la sospecha, dado que podían ser internados, no los autores de crímenes y delitos, sino los que eran sospechosos de atentar contra el orden público y la seguridad nacional".

El 18 de noviembre de 1939, se publica un decreto del gobierno Daladier que generaliza la posibilidad de detener cualquier sospechoso e internarlo en un centro vigilado. El artículo primero de este decreto dice que "los individuos peligrosos para la defensa nacional y para la seguridad pública pueden, por decisión del prefecto, ser alejados por la autoridad militar de los lugares en donde residen y, en caso de necesidad, ser obligados a residir en un centro designado por decisión del Ministro de Defensa Nacional y de la Guerra y del Ministerio del Interior". Se encuentra aquí expuesto el marco jurídico que va a servir para crear 
campos de internamiento duraderos. Es también importante considerar que en base a estos decretos serán internados en el Sur de Francia números muy grandes de españoles. Se sabe que al final de la III ${ }^{a}$ República, habían pasado la frontera 465.000 españoles que huían de Franco. Entre estos 350.000 fueron colocados en campos de internamiento. "El internamiento, está decidido por una autoridad administrativa, el Prefecto, y por una duración que no se define. Va dirigido a personas absolutamente inocentes porque no han cometido ninguna infracción o delito. En efecto la medida que los ataca no sanciona los actos concretos y reprimidos en textos legales promulgados, sino una amenaza general que se trata de prevenir sin que ella se concretice en un acto" (Grandmaison, 2007: 36).

Para terminar este análisis de la génesis de la idea del internamiento y sus características, parece útil terminar con una observación de carácter histórico del filósofo Grandmaison (2007: 36). Como hemos visto, el gran desarrollo de las normas sobre el internamiento vino del Sarraut que era ministro del Interior bajo Daladier que era el primer ministro durante la III ${ }^{a}$ República. Grandmaison explica perfectamente lo que ocurre después. "Después de haber dado plenos poderes al mariscal Petain, el régimen de Vichy extiende estas disposiciones, que él no había inventado, a nuevas categorías de personas por textos redactados a iniciativa del ministro del Interior, Marcel Peyrouton, el antiguo residente general en Túnez, que acaba de entrar en el gobierno. Muy activo en este terreno porque había jugado un papel central en la organización de los campos, firma la ley de 3 de setiembre de 1940 que autoriza el internamiento sin juicio de los "traidores a la patria." Basándose en este apoyo legal, Paul Reynard, Edouard Daladier y Leon Blum entre otros, son investigados $y$ detenidos. Un mes más tarde, el 4 de octubre de 1940, las mismas medidas van a ser tomadas contra los "extranjeros de raza judía". Peyrouton que parecía bien entrenado en todas estas cuestiones del internamiento cuando las aplicaba en Túnez va a jugar un papel central en muchas disposiciones contra los judíos (Grandmaison, 2005). Lo que es más curioso es que publica en 1950 un libro (Peyrouton, 1950) en el cual trata de demostrar las continuidades que se daban entre la III a República y el régimen de Vichy. En un momento determinado de su libro dice: "Se ha hablado mucho de campos administrativos o de concentración abiertos y llenados por el gobierno de Vichy. Esto no es exacto el que fue el padre de estos (campos administrativos), él los reservaba a los Comunistas".

Todas estas observaciones indican que la idea y la práctica del internamiento tuvo en estos momentos una enorme dimensión expansiva, y parece terrible que esa expansión lleva a que ella sea aplicada a algunas de las personas como Daladier que había sido uno de los que más habían defendido esta práctica. No queremos seguir analizando históricamente lo que la realidad de los campos o centros de internamiento representaban porque pensamos que con los elementos que hemos ofrecido se pueden desentrañar bastante bien sus características y consecuencias que ahora se van a explicar. De todas maneras, y como resumen de lo que el internamiento y los campos representan, queremos traer a colación 
unas observaciones de Bernardot (2007: 51-52). Como resultado de la historia que se acaba de esbozar "el campo entra en el terreno de lo normal. Banalizado como espacio del refugiado, ha sido integrado en la política de gestión de los flujos migratorios y se ha vuelto a utilizar progresivamente como espacio represivo. Como recuerda Robert Pandreu, antiguo director de la seguridad... "el internamiento administrativo no es contrario al Estado de Derecho" y es eficaz, aunque sólo sea porque da materia a un control generalizado por los poderes públicos y está liberado del control judicial. El encarna, a pesar de su modernidad renovada sin cesar, el arcaísmo nacional estatista liberado de la idea de culpabilidad y de las penas individuales. Justificado por las autoridades para cuidar la seguridad del estado, y presentado como un medio de luchar contra la inseguridad multiforme de la globalización, está tolerado por la opinión pública de las democracias occidentales en cuanto que se oculta a su mirada y conocimiento".

Teniendo estas observaciones en cuenta, que como es obvio vamos a utilizar en la interpretación de lo que ocurre en España, vamos a describir algunos aspectos de lo que ocurre en nuestro país y posteriormente trataremos de ofrecer una interpretación más teórica de los asuntos. Vamos a partir de algunas observaciones de los inmigrantes que hemos entrevistado y otros datos de fuentes escritas. A pesar de que lo hemos intentado siguiendo todos los procedimientos aconsejados, no se ha podido entrar en ningún centro de internamiento para extranjeros, por esta razón la reconstrucción de la situación de los inmigrantes en ellos es puramente fragmentaria.

Entre los inmigrantes que hemos entrevistado, la mayoría de los internados habían estado en Tenerife. Dos habían estado en Ceuta y uno en Melilla. Otros habían estado en Málaga. Algunos habían estado en Cataluña y unos pocos en Madrid (2 ó 3). A veces era difícil saber donde habían estado porque hablaban "de una isla" o de "un sitio," "me parece que en Barcelona." Dado lo fragmentario de las informaciones, vamos a fijarnos en algunos datos tomados de fuentes escritas.

Comenzaremos por un informe llevado a cabo por la Organización "Human Rights Watch" (2002), al que no hemos tenido más que acceso en francés. Los trabajadores de esta organización visitaron los centros de internamiento de Fuerteventura y Lanzarote, y ofrecen unas conclusiones que son muy interesantes. Lo primero que subrayan es que las condiciones de retención son inferiores a las normas fijadas por la legislación nacional española y el derecho internacional. Estas condiciones se concretizan en lo siguiente: aislamiento total, no hay teléfono ni posibilidades de visita. Los médicos que trabajaban voluntariamente han parado de trabajar en 2002 para protestar por las condiciones sanitarias, que consideraban "muy preocupantes." La precariedad de la situación de los extranjeros estaba muy acentuada por las condiciones de hacinamiento. Por seguir con datos de la misma isla, el periódico "La Opinión" de Tenerife decía el 26 de noviembre de 2008 (seis años más tarde del informe de Human Rights Watch), que una serie de 
asociaciones de inmigrantes (La Asociación Cultural Colectivo de Inmigrantes de Canarias, la Asociación Senegalesa de Lanzarote y la Asociación Socio-cultural de Uruguayos de Lanzarote), fueron a visitar a las organizaciones políticas, al Diputado del Común (Defensor del Pueblo), etc. protestando por el mal trato de los niños cuando llegan a lo que se llama el CAM (Centro de Acogida de Menores Extranjeros), de Lanzarote. Los niños se han quejado de que, cuando ellos han dicho que no comían cerdo y que por ello no podían comer platos que tuvieran esta carne, no les daban otra comida sino que los dejaban sin comer. Otros niños se quejaban de que dado que muchos de ellos estaban acostumbrados a comer con las manos, cuando comían así o intentaban comer así, el alimento les era quitado inmediatamente como castigo. El presidente de la Asociación Cultural de Colectivos Inmigrantes de las islas Canarias, Guelage Gano, declaró que un niño se había quejado hace pocos días de mal trato de un "cuidador" que le dijo: "Tú conocías las normas del Centro cuando has entrado en él, si no te gustan puedes marcharte, 'moro de mierda, hijo de puta'"(!).

Enseguida vamos a analizar los datos que se han expuesto, pero para situar un poco el contexto en el que se producen estas llegadas se puede ofrecer un conjunto de datos tomados de los medios de comunicación que son bastante llamativos. Según Público (17 de febrero de 2009, pag. 28), el 16 de febrero los equipos de salvamento marítimo habían encontrado los cadáveres de 17 inmigrantes africanos que viajaban en un cayuco que había naufragado un día antes por la tarde a 20 metros de la costa del noroeste de Lanzarote. En conjunto murieron, más o menos, 21 personas africanas (la mitad de ellas menores de edad), que viajaban en aquella embarcación. Trece de los fallecidos eran muchachos pequeños y además también venía una niña pequeña de 6 años. También venía una mujer embarazada de ocho meses. El Centro Coordinador de Emergencias y Seguridad seguía buscando otras tres personas que podrían estar muertas. Con ellas el número de muertos llegarían a 24. Es claro que se trata de un número de muertos enormemente alto. Había seis supervivientes de los que la policía tenía constancia. Cinco, de estos seis, habían sido internados en el Hospital Doctor José Molina Orosa de Lanzarote con síntomas de hipotermia. Hay que subrayar las malas condiciones en las que llegan estos inmigrantes. El cayuco en el que llegaban venía de Tánger, el trayecto es bastante corto, no llegaba a 24 horas, y, por ello, los únicos síntomas que presentaban los que llegaban eran de hipotermia. En el tiempo al que nos referimos en este momento, lo más frecuente era que los africanos negros salieran de las costas mauritanas, pero este cayuco había salido de Marruecos. Este es un fenómeno que siempre ha estado presente. En las entrevistas que se han hecho para este trabajo, se presentan los dos casos. Es decir, al mismo tiempo que salían inmigrantes desde el norte de Senegal, salían otros del Sur (Casamance), de Guinea Bissau o incluso más al Sur. Otros salían de Mauritania. Pero estos lugares nunca han copado todos los puntos de salida. Marruecos siempre ha sido 
un punto de salida hacia España y Canarias en concreto. A veces salían del Norte de Marruecos y otras veces del Sur. La diferencia entre unos puntos de partida y otros está en que la distancia y duración del viaje es mucho menor en el caso de salir de Marruecos que en el caso de otros países africanos. Además de esto hay que tener en cuenta las condiciones del mar que también hacen la travesía más difícil. Un ejemplo de esta situación es precisamente el caso que estamos describiendo en donde las condiciones terribles de la mar en las zonas costeras han producido las desgracias de las que se ha hablado. De todas maneras, es evidente que la duración de la travesía influye mucho en las condiciones físicas en las que se encuentran los inmigrantes cuando los internan en los CIEs. En las entrevistas decían que venían tan apretados que no se podían mover en todo el viaje y por ello al principio no podían andar. A veces estas dificultades les duraban 10 ó 15 días. Todos estos problemas hacían que los internados en esos centros no se muevan rápido ni tampoco respondan con prontitud a lo que les dicen los policías. Entonces la reacción de los agentes de la autoridad es decir que son "idiotas". Un inmigrante entrevistado me decía que él no entendía nada cuando estaba en el CIE pero una palabra que se repetía continuamente y que todos entendían era "idiota”.

Volviendo al caso del naufragio en Lanzarote que estábamos describiendo es de subrayar que la Consejera Canaria de Bienestar Social, Juventud y Vivienda, Inés Rojas decía que los cinco supervivientes que fueron trasladados al Hospital "nos preguntan todo el rato por los niños que viajaban en la patera, sobre todo por una niña muy pequeña, pero no les podemos contar aún la situación. Y nos hablan de menores de tres o cuatro años".

En este caso el cayuco llegó a Lanzarote sin que fuese detectado por el Frontex (la Agencia Europea de Fronteras Exteriores), y, por ello, los náufragos fueron auxiliados por un vecino del pueblo más cercano, Teguise, que con la ayuda de otros vecinos los fueron subiendo "a todos a un salvavidas atado a un cabo porque la marea estaba muy dura y el oleaje dificultó mucho el rescate". Con esta descripción no se ha querido hacer nada más que describir la llegada de los inmigrantes, si bien es verdad que algunas de las condiciones en las que llegan son bastante extremas.

Antes de continuar analizando desde un punto de vista más teórico lo que los CIEs o campos representan para los migrantes, queremos hacer algunas observaciones sobre el CIE de Málaga, únicamente porque algunos de los inmigrantes que entrevistamos habían estado allí, y, al final se plantearán algunas cuestiones sobre el de Madrid en Aluche.

El CIE de Málaga ha tenido una historia larga y bastante complicada, como por otra parte todos los CIEs. Se puso en funcionamiento en 1990, pero en 1992 varias ONGs insistían en que el edificio amenazaba ruina y "su situación era deplorable". Se lleva a cabo entonces la primera remodelación del centro. A raíz de ella, visitaron el lugar los asesores del Defensor del Pueblo Andaluz. Entre ellos estaba Sebastián de la Obra a quién yo entrevisté al respecto. Lo que se encontraron no era precisamente para sentirse 
satisfechos. Los internos estaban todo el tiempo encerrados en una habitación "dado que no había dotación de policía que permitiese el uso del patio" (Público, 28 de noviembre 2008: 30). Con esto se quiere decir que la dotación de la policía para vigilancia era escasa y por ello, al no poderlos vigilar convenientemente los mantenían encerrados en habitaciones. Se descubrió que no había teléfono y que las condiciones de limpieza eran muy preocupantes. La comida era escasa y muy mediocre. Por ejemplo, la cena era sustituida siempre por un bocadillo. Por fin, también se observa que hay una ausencia total de mobiliario. Lo único que tenían eran literas en las que se hacinaban los internos. En 1994, 46 inmigrantes se pusieron en huelga de hambre en protesta por las condiciones en las que se encontraban. En 1995 se denunciaron malos tratos y una mujer brasileña denunció a un agente de la policía por abusos. "El acusado fue condenado por una falta de vejación injusta de carácter sexual, según las ONGs” (Público, 28 noviembre 2008). En 1996, 103 inmigrantes fueron expulsados, después de haber sido sedados y transportados en aviones militares, a Guinea Conakry, Senegal, Mali y Camerún. En 1997 visitó el Centro una delegación del Comité para la prevención de la tortura del Consejo de Europa, porque se había planteado una denuncia en toda regla. Entre 1998 y 1999 se producen tres incendios con personas intoxicadas. Posteriormente se llevaron a cabo obras y el Centro se duplicó en cuanto a su capacidad porque se empiezan a admitir 125 personas en vez de las 75 que había antes. En esta ampliación se introduce un módulo para albergar a familias y un segundo patio. A pesar de estos cambios el Defensor del Pueblo Andaluz denunció en 2002 las condiciones absolutamente precarias de este Centro. Habla de "condiciones peores que las de las cárceles, visitas de familiares limitadas a diez minutos, mamparas de cristal, los internos apenas ven la luz del día". Como se puede observar, las mamparas de cristal pueden ser muy útiles para la vigilancia de los internos, pero convierten el centro en una especie de "panopticum" en donde cualquier mínima defensa de la esfera de lo privado es absolutamente imposible.

Mayer (2004) cuenta, con un cierto humor ácido, que dos diputados belgas, después de haber visitado el centro cerrado de Brujas en 1999 dijeron que las condiciones eran "correctamente inhumanas." Con ello querían decir que, a pesar de las condiciones estrictas de vigilancia, los retenidos tenían acceso a actividades deportivas, talleres artísticos y bibliotecas. Se organizaban fiestas, barbacoas, competiciones deportivas conciertos de vez en cuando. Por otra parte, las salidas son milimetradas desde el punto de vista del tiempo, las sanciones son muy duras y los internos son llamados siempre por un número. Esto es evidente que subraya el carácter carcelario del centro, pero, como se puede observar las condiciones "inhumanas" del Centro de Brujas no tienen nada que ver con las condiciones mucho más inhumanas de lo que ocurre en Málaga.

Volviendo a este último Centro se pueden relatar algunos de los últimos acontecimientos que se han podido conocer. En la segunda quincena de noviembre de 2008 fueron 
internadas en este Centro una madre y una niña de cuatro años. El padre y esposo fue internado en una zona diferente de aquella en la que él estaba. La madre y la niña fueron repatriadas el 20 de noviembre en un vuelo regular y el padre al enterarse se encontró tan mal que el médico tuvo que suministrarle ayuda. La familia afirmaba que ellos venían de Freetown (Sierra Leona), pero los repatriaron a Lagos (Nigeria), quizás porque (sospecho yo) hay vuelos frecuentes a Lagos. Más adelante hay que analizar con detenimiento este acontecimiento que necesita una interpretación detenida. De todas maneras, se siguen acumulando los informes sobre este Centro. En 2006, tres expertos europeos llegaron a la conclusión de que el CIE de Capuchinos (así se llamaba el Centro de Málaga), carece de las mínimas condiciones para el internamiento de seres humanos. En 2007 vinieron unos funcionarios enviados por el Parlamento Europeo y decían que "las condiciones físicas y de higiene en las que se hacinaban los internados eran deplorables". El abogado malagueño José Luis Rodríguez, que trabaja sobre problemas de extranjería decía que, en el mejor de los casos, las condiciones de este Centro eran parecidas a una cárcel, cuando todo el mundo sabe que no es una cárcel. El representante de Médicos del Mundo, Hervé Bertevás censuraba en su informe las condiciones higiénicas y sanitarias y el bombero, Lorenzo Álvarez, decía que las medidas de protección contra incendios eran muy malas. El responsable de Inmigración de la Asociación pro Derechos Humanos dice que no "es digno de seres humanos." El Defensor del Pueblo Andaluz, el Señor José Chamizo, ha pedido varias veces que se "dignifiquen las instalaciones del Centro de Capuchinos" y el Portavoz de la Coordinadora de Inmigrantes de Málaga, Gerardo Márquez, dice que "es el peor de Europa" (Público, 28 de noviembre 2008). Un conocido que no quiere que se cite su nombre pero que ha visitado bastantes Centros de este tipo, no sólo en España sino en algunos otros lugares del Sur de Europa, tales como Malta, Grecia e Italia, cuando comentaba todos estos testimonios sobre el Centro de Málaga, al ver la afirmación de que era el peor de Europa, me contestó que esto es falso, "no es ni el peor de España ni tampoco de Europa.”

El último CIE del que hablaremos aunque sea de un modo sumario es el de Madrid en Aluche. Hacia la mitad del mes de febrero de 2009 tres ONGs (SOS Racismo Madrid, Ferrocarril Clandestino y Médicos del Mundo), presentaron una denuncia en los Juzgados de Madrid (Plaza de Castilla), en la que sacan a la luz malos tratos y agresiones físicas a inmigrantes. Había cartas escritas de 16 internos en este Centro que se quejaban de estas agresiones físicas y verbales, y que, también, hablaban de condiciones de habitabilidad e higiene que dejan mucho que desear. Entre las quejas concretas que plantean están: "Sólo hay tres retretes para 66 personas. También hay problemas de espacio" (El País, 18 de febrero 2009). El hacinamiento es también muy alto, hay 10 personas para vivir en una habitación de 20 metros cuadrados. Hay cinco teléfonos, pero sólo funcionan tres. Con respecto a las condiciones de la alimentación (objeto de queja en todos los casos que hemos encontrado y que aparece continuamente en nuestras entrevistas), "los extranjeros 
tienen que comer alimentos en mal estado" (Público 18 de febrero 2009), y encuentran en las bandejas restos de alimentos del día anterior. No pueden cumplir con sus hábitos higiénicos porque frecuentemente cuando aumenta el número de internos no tienen agua caliente. Una periodista de El País, que pudo entrar al centro de Internamiento, dice que el interno que fue a visitar se quejaba de que los policías les gritan. Mientras ella estaba allí, había un inmigrante boliviano que había venido a visitar a un amigo. Al tener el móvil encendido vino un policía y empezó a gritarle: "El móvil debe estar apagado. ¿No escuchaste o es que no entiendes castellano?”. Una inmigrante venezolana que había venido a visitar a su novio, decía: "Si nos tratan mal a nosotros que estamos fuera, cómo les tratarán a ellos". La periodista a la que nos hemos referido no puede obtener mucha información. Lo único que dice es que "dormimos ocho personas en literas en el mismo cuarto. Nos sacan a jugar al futbol por la tarde. La luz la apagan a las doce y media". Como se puede observar, el trato se acerca un poquito más a las "condiciones correctamente inhumanas" de las que hablaban los dos parlamentarios belgas. De todas maneras, la comunicación con los internos se encuentra muy restringida. Se lleva a cabo en una mesa que está separada de otra mesa por cristales gruesos y opacos y al lado de cada una de ellas hay un policía. Al final de los cinco minutos que la periodista pudo tener comunicación con el extranjero sin papeles, el boliviano a quién la policía le había reñido dijo que su amigo le había insistido en que la comida era muy mala. Por estas mismas fechas hubo denuncias de malos tratos físicos de carácter grave. Las ONGs a las que nos hemos referido describieron el caso de Ali Kamel, un extranjero de origen argelino que fue agredido físicamente por policías del Centro. Fue víctima de doble fractura en un brazo y otras heridas que se produjeron cuando descansaba en su habitación, "al interno 31 " de origen dominicano le dieron con una porra en los labios por pasarse de tiempo en una llamada telefónica. Como se puede observar los internos son designados por números. Este es un procedimiento general en algunos CIEs.

En Hoya Fría (Tenerife),se identifica a los retenidos con un número que ha sido rotulado en su propia ropa, como ha denunciado el Defensor del Pueblo en su informe de este año. El Señor Mujica también ha criticado que los policías en el CIE de Aluche en Madrid paseen entre los internos con sus defensas en la mano, en vez de llevarlas en el cinturón. Estos CIEs o Campos se constituyen como una especie de espacios extraterritoriales, lo cual es lo mismo que me quería decir el inmigrante que yo entrevistaba. El me decía que ellos eran apátridas, y cuando yo preguntaba por lo que esto quiere decir, él me respondía que tenían que ocultar su lugar de origen porque si lo manifestaban inmediatamente los repatriaban. Evidentemente este ocultamiento representa una ruptura radical con su lugar de origen. Por otra parte, también se da un corte radical con el país de llegada porque, como el inmigrante me decía, "ustedes no nos quieren." Esta doble ruptura se manifiesta en el carácter cerrado del CIE que está aislado del mundo exterior, y este 
aislamiento se amplifica por la enorme dificultad que tienen en comunicarse. En muchos de los centros no hay ni siquiera teléfono, y, en aquellos en donde los hay, son tan escasos que es muy difícil comunicarse, por eso los castigos totalmente desproporcionados tales como pegarle a alguien con la porra en los labios cuando se pasan del tiempo autorizado. Esto implica, en primer lugar, la reducción de la persona a una especie de individuo aislado. Este fenómeno del aislamiento es algo que está presente en los inmigrantes que hemos entrevistado. Cuando se preguntaba por la compañía o las amistades o ayudas que habían tenido por el camino antes de llegar a España siempre contestaban que ellos eran "muy pobres" y venían "solos". Poco a poco, se fue comprendiendo que todo eso que se dice, de que en los procesos migratorios uno de los fenómenos fundamentales que los estructuran son las redes de relaciones, no tiene ninguna vigencia entre los inmigrantes africanos negros y pobres que nosotros entrevistamos. Incluso, es curioso que después de un cierto tiempo en España (algunos llevaban aquí 3 ó más años), los entrevistados se quejaban de que estaban solos. A lo sumo hablaban de un amigo o conocido con el que compartían la habitación o la vivienda pero al que no veían más que un poco tiempo aunque fuera para cocinar juntos. En este tipo de migración, lo que se da es un proceso paulatino de pérdida de relaciones, o de ruptura de relaciones, debido a la escasez de recursos y al proceso largo y penoso que el viaje de la migración representa. Además, la llegada al Campo o Centro de internamiento subraya y amplifica este aislamiento con respecto al lugar de origen y el de llegada. Además de esto, se produce un corte radical aún con respecto a las relaciones más cercanas como pueden ser las relaciones de esposa esposo o de padre hijo. El ejemplo de lo que ocurre en el Centro de Capuchinos de Málaga es bastante llamativo y significativo. Entran en él un padre, una madre y su hija. Lo primero que se hace es separar al padre de la madre y de su hija y, lo que es más grave, devuelven a Lagos en Nigeria, primero a la madre y la niña, y otro día devuelven al padre. No le dicen nada a éste hasta que no lo pregunta una vez que la madre y la niña se habían ya marchado con lo cual lo que "de facto" se consigue es romper, esperemos que temporalmente, las relaciones quizás más intensas de este individuo que se queda solo, un individuo sin relaciones ni atributos. Este proceso que aquí adquiere aspectos trágicos y cómicos es lo que se produce en estos centros, la creación de individuos aislados, sin relaciones. Isin y Rygel (2007) hablan de espacios de frontera, zonas y campos que tienen en común alojar en la extraterritorialidad a ocupantes que no son nada, individuos indefinidos y dignos del mayor desprecio, "neither subjects nor objets but abjects," no son ni sujetos ni objetos sino abyectos.

Si desde el punto de vista de las relaciones sociales pasamos al campo de los derechos, encontramos algo muy parecido. En su libro sobre los Orígenes del Totalitarismo, Arendt describe la situación contradictoria de aquellos que son hombres sin ser ciudadanos. " $L a$ pérdida de la nacionalidad de una gran parte de los refugiados entre las dos guerras, trae consigo la pérdida de su estatuto cívico, de su pertenencia a un territorio, a un gobierno, 
a un sistema jurídico. Como consecuencia de esto, se sigue que la pérdida de los derechos del ciudadano va unida, intrínsecamente y de una manera necesaria, a la pérdida de los derechos del hombre y trae consigo la reducción del sujeto de los derechos a una vida despojada de todo derecho y por ello de todo lazo social, que está protegida en el mejor de los casos por las organizaciones humanitarias y no políticas". Sin referirse a ellos, Arendt está describiendo la situación de los inmigrantes irregulares en los centros donde son internados. Efectivamente, lo que se produce en el internamiento es, en primer lugar, privar a la persona de su libertad y además abolir en gran medida su condición de titular de derechos. Prácticamente no le queda más que el derecho de ser deportado, devuelto a su país de origen y la libertad de volver a él. Se trata precisamente de un derecho y una libertad que el inmigrante irregular no quiere ejercer. Los lugares de internamiento tienen como misión registrar los inmigrantes sin papeles, vigilar sus actividades y localizarlos para poder llevar a cabo una vuelta no deseada a su lugar de origen. Con respecto a los derechos, es evidente que, aunque bastante escasos, todos dirán que existen. El problema es el ejercicio práctico de los mismos. La dificultad está en la enorme discrecionalidad y el margen de maniobra que tiene la administración, bien porque ella es reconocida, o porque las leyes son a veces muy complejas e imprecisas. Si a esto se une que no hay ninguna organización que sirva para ayudar o que favorezca el ejercicio efectivo de los derechos se comprende perfectamente cómo el problema fundamental está en la falta de voluntad de reconocer los internados como sujetos de derecho. En las últimas peticiones de los internados del CIE de Madrid (Aluche) a la Administración solicitan "una Asistente Social que nos escuche y nos dé soluciones". También solicitan "un supervisor que vigile por los derechos humanos". Todo esto indica que no hay ninguna persona ni organización que pertenezca a lo que se puede designar como al orden de lo humanitario, que intervenga en estos centros de internamiento, y desde luego no parece que haya nadie que vele por los derechos humanos, ni tampoco por el ejercicio efectivo de los derechos. El único órgano de control dentro de estos centros es la policía que, por mucho que se diga, no tiene como misión principal estos menesteres. Todo esto lo explica muy bien Arendt que en los Orígenes del Totalitarismo, publicado en el mismo año en que se funda el Alto Comisariado para los Refugiados de la ONU, dice refiriéndose a los sin estado que "el estado-nación, incapaz de presentar una ley para aquellos que habian perdido la protección de un gobierno nacional, deja el problema en manos de la policía". En el caso de los inmigrantes irregulares en los Campos o centros es absolutamente aplicable esta observación. Se trata como decía nuestro informante de "apátridas". Es posible que un jurista estricto no admita esta cualificación desde el punto de vista del derecho, pero, desde el punto de vista de las consecuencias y de la situación real, lo que decía el inmigrante es absolutamente exacto. Lo que el campo o el centro trae consigo es un fenómeno bastante curioso. No se pueden olvidar las palabras usadas en la terminología española, "Centro de Internamiento para Extranjeros." Se trata de 
extranjeros y no de inmigrantes, y hay que reconocer que si bien en la cualificación de estos campos como centros hay un elemento de eufemismo, la palabra extranjero es un término descriptivo perfecto. Spire, (1999) dice que "la definición misma de retención llevará a cabo este trabajo de categorización y de separación entre los internados y los otros, tendiendo a producir como grupo particular estos extranjeros absolutos que son los expulsables". La misión fundamental de los Centros es precisamente la legitimación de la expulsión desde un país, en donde se le niegan todos los derechos, a otro en donde no hay ningún interés en recibirlo. Es evidente que se trata de construir una categoría nueva que son "los extranjeros absolutos," otra manera de describir lo que nuestro inmigrante quería decir con el término de "apátrida". Ya se puede sospechar de los derechos que se reconocen a los extranjeros absolutos.

Por otro lado, hay que tener en cuenta que, como ya hemos dicho, antes de ser internados en el Centro, los inmigrantes que hemos entrevistado vivían ya en una situación de una muy fuerte individualización y aislamiento. Pero esto se agudiza mucho más en el centro de internamiento. Como lugares de encierro, estos aseguran un cierre social cortando al extranjero de las interacciones y relaciones en las que tomaba parte previamente. Al tener lugar este proceso de aislamiento y de ruptura de las relaciones con los otros, tanto la ruptura de relaciones como la desaparición y disminución enorme de los derechos lo que traen consigo es, parafraseando a Foucault, la supervivencia del cuerpo del extranjero y a la vez su desaparición de la escena política.

El filósofo italiano Agamben (1997), explica bastante claramente lo que es la "vida desnuda" poniéndolo en relación con Aristóteles. Sin querer entrar ahora en disquisiciones filosóficas en las que no me considero experto, puede ser interesante comprender que, para Aristóteles, hay que distinguir entre Zoé (el simple hecho de vivir una vida exenta de toda calificación, una simple vida natural), y Bios (una vida cualificada, política o filosófica). No tratamos de elucidar todo lo que Agamben afirma acerca de lo que es la "vida desnuda". Partiendo de la distinción entre Zoé y Bios, se puede decir que la vida desnuda es lo que Aristóteles designa como Zoé. Lo que se produciría en los Campos o Centros de Internamiento es la reducción del extranjero a la "vida desnuda" y su destrucción como sujeto de derechos y relaciones y por lo tanto de su carácter político. La protesta generalizada sobre la mala calidad y escasez de la comida llama la atención sobre el hecho de que a duras penas se asegura el mantenimiento de una supervivencia biológica. 


\section{REFERENCIAS BIBLIOGRAFICAS}

Agamben, Giorgio (1995) Qu'est-ce qu'un camp? En: Moyens sans fins, Notes sur la

politique. Paris: Payot/Rivages.

Agamben, Giorgio (1997) Homo sacer. Le Pouvoir souverain et la vie nue. Paris: Le Seuil.

Asier, Michel (2008) Gerer les Indesirables. Des Camps de Refugiés au Gouvernement. Paris: Humanitaire, Flammarion.

Benhabiles, Cherif (1914) L'Algerie française vue par un indigène. Argel: Imprimerie Orientale.

Bernardot, Marc. Conferencia impartida el 25 de enero de 2002 (ms).

Bernardot, Marc (2002) "Le pays aux mille et un camps. Approche Socio-historique des espaces d'internement en France au XXe siècle”. Cahiers du Ceriem, 10.

Bernardot, Marc (2003) “Des Camps en France (1944 - 1963)”. Plein Droit, 58.

Bernardot, Marc (2004) "Entre répression policière et prise en charge Sanitaire et sociale: le cas de centre d'assignation du Larzac (1957-1963)”. Bulletin de L'IMTP, 80.

Bernardot, Marc (2005) “Etre interné au Larzac: les algériens dans les centres d'assignation à résidence surveillée (1958 - 1962) ”. Politix, nº 69.

Bernardot, Marc (2005) "Au cour de Saint Mitre: sociologie d'un centre de séjour surveillée (1944-1945)", Déviance et Société.

Bernardot, Marc (2007) "Les Mutations de la figure du Camp". En: Le Cour Grandmaison,L'Huilier y Valluy (eds.) Le Retour des Camps. Paris: Autrement.

Bietlot, Mathieu (2005) "Le camp, révélateur d une politique inquiétante de l'étranger". En: L'Europe des Camps. La mise à l'écart des étrangers. Cultures et Conflits, 57.

Caloz-Tschopp, Marie Claire (2000) Le Sans-État dans la philosophie d'Hannah Arendt. Lausanne: Payot.

Courau, Henri (2007) Ethnologie de la Forme Camp de Sangatte. Paris: Editions des Archives Contemporaines.

Engbersen, George (2001) “The Unknown City”. Berkeley Journal of Sociology, 40.

Intraud, Caroline S y Perrouty, Pierre Arnand (2005) "La diversité des camps d'étrangers en Europe: Présentation de la carte des camps de Migreurop”. En: L'Europe des Camps. La mise à l'écart des étrangers. Cultures et Conflits, 57. 
Laacher, E y Rechtenwald, G (1923) Traité Elémentaire de la Législation Algérienne. Paris: A Rousseau.

Le Cour Grandmaison, Olivier (2005) Coloniser, Exterminer. Sur la guerre et l'état colonial. Paris: Fayard.

Le Cour Grandmaison, O, L'Huilier, G y Valluy, J (eds.) (2007) Le Retour des Camps. Paris: Autrement.

Martínez Veiga, Ubaldo (2006) "Absolute Poverty of Illegal Immigrants in Spain; A Growing Problem". En: Petmesidou, Maria y Papatheodorou, Cristos (eds.). Poverty and Social Deprivation in the Mediterranean. Trends, Policies and Welfare Prospects in the New Millenium. Londres: Zed Books.

Martínez Veiga, Ubaldo (2007) “Migraciones y Racismo". En: Diccionario de Relaciones Interculturales. Madrid: Complutense.

Massonié, Gilbert (1909) La Question indigène en Algérie. L'internement des indigènes, son illégalité. Paris: Ligue des Droits de l'homme.

Mayer, Noel (2004) “Les Centres fermés: vu de l'intérieur". En: Perrouty (dir.). La mise à l'écart de l'étranger. Centres fermés et expulsions, Bruselas: Labor.

Migreurop (2007) "Les Camps d'Etrangers en Europe”. En : Le Cour Grandmaison, L'Huilier y Valluy (eds.). Le Retour des Camps. Paris: Autrement.

Pechanski, Denis (2002) La France des camps. L'Internement, 1938 - 1946. Paris: Gallimard.

Peyrouton, Maurice (1950) Du service publique à la prison commune, Paris: Souvenirs, Plon. 